\title{
Measured and Predicted Vapor Liquid Equilibrium of Ethanol-Gasoline Fuels with Insight on the Influence of Azeotrope Interactions on Aromatic Species Enrichment and Particulate Matter Formation in Spark Ignition Engines
}

Stephen Burke Colorado State University

Robert Rhoads University of Colorado

Matthew Ratcliff and Robert McCormick National Renewable Energy Laboratory

Bret Windom Colorado State University

Citation: Burke, S., Rhoads, R., Ratcliff, M., McCormick, R. et al., "Measured and Predicted Vapor Liquid Equilibrium of Ethanol-Gasoline Fuels with Insight on the Influence of Azeotrope Interactions on Aromatic Species Enrichment and Particulate Matter Formation in Spark Ignition Engines," SAE Technical Paper 2018-01-0361, 2018, doi:10.4271/2018-01-0361.

\section{Abstract}

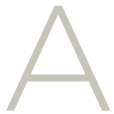

relationship has been observed between increasing ethanol content in gasoline and increased particulate matter (PM) emissions from direct injection spark ignition (DISI) vehicles. The fundamental cause of this observation is not well understood. One potential explanation is that increased evaporative cooling as a result of ethanol's high HOV may slow evaporation and prevent sufficient reactant mixing resulting in the combustion of localized fuel rich regions within the cylinder. In addition, it is well known that ethanol when blended in gasoline forms positive azeotropes which can alter the liquid/vapor composition during the vaporization process. In fact, it was shown recently through a numerical study that these interactions can retain the aromatic species within the liquid phase impeding the in-cylinder mixing of these compounds, which would accentuate PM formation upon combustion. To better understand the role of the azeotrope interactions on the vapor/liquid composition evolution of the fuel, distillations were performed using the Advanced Distillation Curve apparatus on carefully selected samples consisting of gasoline blended with ethanol and heavy aromatic and oxygenated compounds with varying vapor pressures, including cumene, p-cymene, 4-tertbutyl toluene, anisole, and 4-methyl anisole. Samples collected during the distillation indicate an enrichment of the heavy aromatic or oxygenated additive with an increase in initial ethanol concentration from E0 to E30. A recently developed distillation and droplet evaporation model is used to explore the influence of dilution effects versus azeotrope interactions on the aromatic species enrichment. The results suggest that HOV-cooling effects as well as aromatic species enrichment behaviors should be considered in future development of predictive indices to forecast the PM potential of fuels containing oxygenated compounds with comparatively high HOV.

\section{Introduction}

$n$ most internal combustion engines (ICEs) the complex energy conversion process begins with the injection of a liquid fuel followed by the atomization and vaporization of the fuel, which then must mix with air before finally reacting via combustion converting the chemical energy of the reactants into heat and then work. Each step in this thermodynamic process plays an important role in ensuring that the chemical energy is converted to work efficiently with minimal emission of harmful pollutants. In spark ignition (SI) ICEs it is critical for the fuel and air to mix prior to the initiation of the spark which commences combustion.
A uniform mixture is less likely to auto-ignite (i.e. engine knock) and results in minimized emissions of soot, NOx, and unburned hydrocarbons (UHC) $[\underline{2}, \underline{3}]$. In direct injection spark ignition (DISI) engines, the fuel is injected directly into an air filled combustion chamber rather than in an intake port. DISI has advantages stemming from evaporative cooling effects that can provide increased resistance to knock and allow for higher mass loading of reactants into the cylinder creating additional boost and fuel efficiency. However, to ensure a high degree of mixing between the reactants prior to combustion, the spray must vaporize quickly and completely before the mixture is ignited. As such, in modern engines that 
employ these injection strategies, the spray and evaporation process can play an enormous role on the engine performance and emissions, especially particulate matter (PM) emissions.

Motor vehicles emit fine particulate matter (PM) as products of incomplete combustion. PM emissions are primarily composed of soot and soluble organic compounds which can be toxic and contribute to global warming $[\underline{4}, \underline{5}, \underline{6}$, 7]. Mitigating PM emissions from gasoline (SI) engines has recently become an important issue and challenge. The two key aspects of a fuel which define its propensity to form PM in an SI engine are (1) its chemical pathways or kinetics which lead to soot and (2) its volatility which effects its ability to mix with the air $[\underline{8}, \underline{9}]$. Fuels which have a high $\mathrm{C} / \mathrm{H}$ ratio provide a greater tendency to produce PM because of their tendency to form polycyclic aromatics hydrocarbons (PAHs), especially the case for molecules in the aromatic hydrocarbon moiety [10]. Sooting indices, such as the threshold sooting index (TSI) and the yield sooting index (YSI) have been developed to identify the chemical potential of a particular species to form soot/PM [11, 12]. However, even compounds which have a low TSI or YSI value can still form PM if combusted in a rich environment resulting from slowed evaporation and improper mixing. As such, modern DISI engines, where time for the air and fuel to mix is reduced compared to port injection strategies, tend to exhibit higher PM emissions [13]. For hydrocarbon based fuels these two behaviors can be estimated by relatively simple to measure properties and combined to predict the fuel's potential to form PM in standard engines.

Through empirical methods, the Particulate Mass Index (PMI) was derived which is used to predict the PM potential of a fuel used in SI engines. In general, the PMI is a calculation which uses the fuel composition and the fuel's individual constituent's properties such as volatility and fuel structure to predict the fuel's potential to generate PM in SI engines [14]. More specifically, PMI is a mass weighted function of the volatility and double bond equivalence (DBE) of each species in the mixture (Eq. 1). The DBE, which is a marker of a molecule's carbon bond saturation and $\mathrm{C} / \mathrm{H}$ ratio, represents the chemical potential of that particular component to form PM whereas the vapor pressure at $443 \mathrm{~K}, P_{v}(443 \mathrm{~K})$, is used to describe the constituent's ability to evaporate and mix in a timely manner. Aikawa et al. validated the PMI method of predicting PM using port injected vehicles [14]. Khalek et al. validated the method with DISI vehicles and three pump gasolines, one of which contained ethanol [9]. Though PMI has proven to be effective at predicting a fuel's potential to form PM, especially when the fuel contains no or little (less than $15 \%$ ) oxygenates, PMI has demonstrated less consistency to predict the PM emission potential of fuels which include moderate

$$
P M I=\sum_{i}\left[\frac{D B E_{i}+1}{P_{v}(443 K)_{i}} W t_{i}\right]
$$

levels of biofuel compounds, often under predicting the actual PM emissions of these blends.

Biofuels are increasingly used to reduce life cycle greenhouse gases (GHG). Gasoline (including ethanol blends) is responsible for $23.7 \%$ of the United States' CO2 production, and is a major focus for reducing $\mathrm{CO} 2$ emissions [15].
Ethanol is by far the most prolific biofuel, constituting $79.8 \%$ of the U.S. biofuel energy consumption, and currently provides $6.4 \%$ of the energy consumed by gasoline vehicles [15]. Some studies have shown that ethanol can reduce lifecycle greenhouse gas emissions compared to gasoline [ $[16, \underline{17}]$, and that increasing ethanol content in gasoline blends would provide a decrease in greenhouse gas emissions.

Studies have demonstrated increased knock resistance for intermediate gasoline ethanol blends $[\underline{18}, \underline{19}, \underline{20}, \underline{21}]$. Chupka et al. found that research octane number (RON) increases with ethanol content, but diminishing returns were observed for ethanol concentrations exceeding $30 \%$ by volume $[18,22]$. This makes E30 of particular interest, as it requires less ethanol to produce than high ethanol blends (E50 to E85), while achieving most of the knock-resistance benefits. These results are mirrored by dynamometer experiments by Leone et al. demonstrating that splash blended E30 could improve compression ratios substantially compared to E10 (from 10:1 to 13:1 for the 3.5 L turbocharged DISI engine tested) [23]. Despite the increased compression ratio, the splash-blended E30 allowed for higher mean effective pressure and manifold pressure across the entire engine speed range. Note that match blending for RON allowed for no benefits to compression ratio, mean effective pressure, or manifold pressure, implying that they are a result of the anti-knock properties of ethanol. They estimated that this change would result in a 6-9\% improvement to $\mathrm{CO} 2$ emissions with little change to MPG fuel economy, which was improved over E10 in some cases. Other E30 experiments with the same engine yielded similar results [24].

In addition to the knock resistance effects of ethanol described by the RON, which is measured with a carbureted engine [22], further knock resistance is provided in a DISI engine as a result of charge cooling, which is enhanced by the high HOV of ethanol $[\underline{18}, \underline{19}, \underline{21}, \underline{25}]$. At $25^{\circ} \mathrm{C}$, the HOV for ethanol is $924 \mathrm{~kJ} / \mathrm{kg}$ while that of gasoline ranges from $350-400 \mathrm{~kJ} / \mathrm{kg}$ [26]. Kasseris et al. found that the charge cooling effect of direct injection was equivalent to a $14{ }^{\circ} \mathrm{C}$ cooler intake temperature when compared to port injection for E0 [21]. In the case of E50, this effect was greater than a $30^{\circ} \mathrm{C}$ difference in intake temperature. This cooling effect was equivalent to increasing the fuel octane by 5 for E0 and by 13 for E50 (effective octane number $(\mathrm{RON}+\mathrm{MON}) / 2)$, demonstrating that DISI engines are uniquely able to leverage the properties of intermediate ethanol blends to reduce knock and increase effective compression ratios [27].

While E30 has not been determined to be suitable for existing gasoline engines [28], it is being investigated to enhance the performance of purpose-built engines. Splitter et al. compared the performance of E30 (100.3 RON) to isobutanol 24 (IB24, 96.6 RON) and E0 (90.2 RON) in an engine with either a 9.2 compression ratio for E0 (appropriate for E0) and 11.85 for all fuels (appropriate for E30 and IB24) [29]. E30 at a compression ratio of 11.85 provided the highest brake thermal efficiency of the fuels tested, and allowed the highest load for a given engine speed, including E0 at 9.2 compression ratio, effectively doubling the torque capability for the high compression ratio case. Increases in compression ratio and knock-limited load would allow for downspeeding and downsizing of engines beyond what is possible with E0. However, 
such engines would not be able to utilize E0 effectively, and would not be flexibly fueled.

Nakata et al. investigated the performance benefits of intermediate ethanol-gasoline (111 and $92 \mathrm{RON}$, respectively) blends on a port injected engine [30]. Blends of E0, E10, E20, E50, and E100 were compared. It was found that ethanol blending reduced both charge and combustion temperature, which reduced cooling losses and thus increased thermal efficiency and torque. The improvements to torque showed diminishing returns at E50 and higher ethanol content, due to ignition advance reaching maximum brake torque (MBT) without being knock limited. Of these blends, E20 achieved the most optimal specific fuel consumption (SFC). Studies have also shown that ethanol increases flame front speed and early flame development $[\underline{20}, \underline{31}, \underline{32}, \underline{33}]$. Improvements in combustion dynamic may increase torque at high rpm.

In most cases, past research has shown that ethanol reduces PM emissions $[\underline{19}, \underline{32}, \underline{34}, \underline{35}, \underline{36}, \underline{37}, \underline{38}]$. Generally it is observed that for fuels with low ethanol content, in the range of E0 to E15, ethanol content has minimal impact on PM emissions. At high ethanol concentrations, such as E85, a reduction in PM emissions has been observed, likely due to dilution of PM precursors such as olefins and aromatics.

However, PM emissions have been observed to be increased by ethanol in some cases, particularly in DISI engines due to increased impingement relative to port injection $[1, \underline{19}, \underline{40}, \underline{41}]$. Of particular note is intermediate blends (e.g. E20 to E40) [19, 39, 42], although increases have been observed for low and high ethanol blends as well. Maricq et al. compared sooting behavior in diffusion flames for E0, E20, E50, and E85 blends, and little difference between E0, E20, and E50 was observed [43]. As sooting is predominantly a product of diffusion flames, this implies that for intermediate blends, the prevalence of diffusion flames resulting from improper fuel mixing is more predictive of PM emissions than the fuel chemistry. Storey et al. conducted a DISI study comparing $\mathrm{PM}$ emissions between $\mathrm{E} 0$ and $\mathrm{E} 20$, and found that ethanol decreased PM emissions [37]. However, when they compared E0 and E30 in a different study with the same engine, it was found that E30 resulted in higher particulate mass and lower particulate number than E0 [44]. Chen et al. observed a significant increase in particulate mass and particulate number (PN) for E10 compared to E0 for a DISI engine [41]. These blends used Shell PURA test gasoline as a blendstock, which has $22 \%$ aromatics by volume. The study concluded that this was likely due to ethanol's high enthalpy of vaporization. Chen et al. did a follow up study with the same blendstock for various blends between E0 and E85 [누]. Particulate mass and particulate number were found to increase with ethanol content.

Butler et al. found that an intermediate ethanol concentration resulted in a different correlation between measured PM and PMI in some vehicles tested. In the case of the $1.8 \mathrm{~L}$ Honda Civic, the correlations found for E0 and E10 would under predict the measured PM of E20 [1]. This is shown in Figure 1. While this result did not apply to all vehicles in the study, inconsistency between PM and measured PMI suggests that volatility and double bond equivalence are not the lone chemical and thermophysical properties that are dominant in the formation of soot in SI engines. Note that this differs
FIGURE 1 PM testing performed by Butler et al. on a $1.8 \mathrm{~L}$ Honda Civic [1]. Note that there are different correlation between PMI and measured PM for EO and E2O.

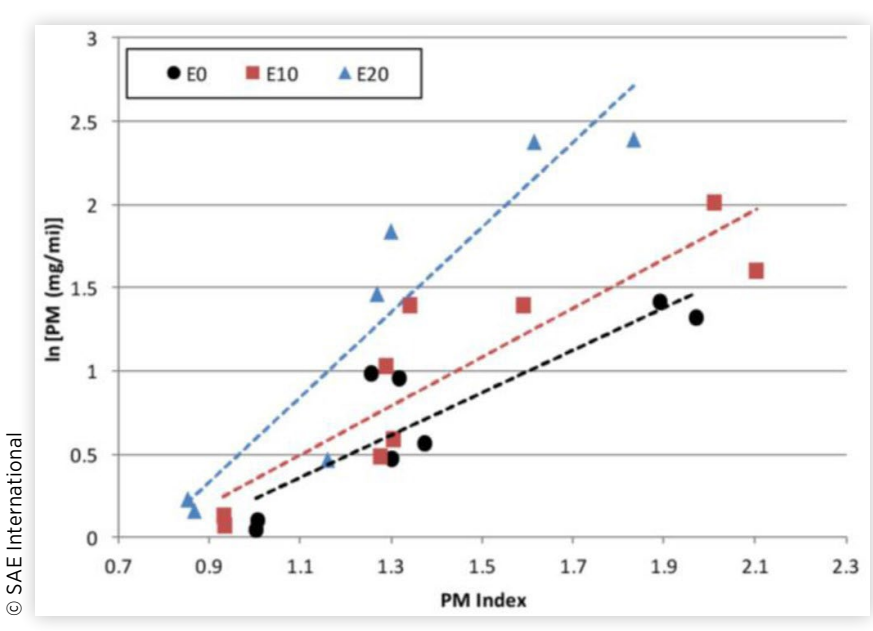

from results obtained by Ratcliff et al. using a DISI engine [19], which found that ethanol did not influence PM emissions, and that PMI was predictive of both particulate number and particulate mass for ethanol containing fuels. In this study, PM decreased as a function of ethanol content, as PMI would predict. Although, it should be noted that higher than expected PM (as suggested by PMI) was noticed for anisole containing fuel blends stemming from these molecule's shorter kinetic pathways to PAHs.

The cause of the high PM emissions for intermediate blends in some studies is not well understood. As Chen et al. postulated, one plausible cause is the enthalpy of vaporization of ethanol $[38, \underline{41}]$. The high HOV may lead to significant cooling of the spray or the cylinder environment, slowing evaporation and increasing droplet lifetimes. Increased lifetimes could increase PM due to either increased impingement, or a less homogenous fuel-air mixture at the start of combustion. Impingement in a direct injection engine can result in films with higher concentrations of low volatility species than the neat fuel, thus leading to diffusion flames with high molecular weight species, which would ultimately result in increased PM $[1, \underline{39}]$. Ethanol and other oxygenates can have non-ideal vapor liquid equilibrium (VLE) effects, such as azeotropes, when blended with gasoline. These effects change not only the volatility of the overall mixture, but preferentially affect the volatility of certain groups and species. This alters the evolution of the vapor and liquid composition over time, and may cause the enrichment of certain species in either the liquid or vapor phases.

In a recent work, Burke et al. numerically demonstrated that the high HOV of ethanol can lengthen droplet evaporation times in a transient engine environment and suppress aromatic evaporation leading to aromatic species enrichment within the evaporating liquid droplet [45]. Expanding on this work, in this study, experimental volatility measurements using the Advanced Distillation Curve approach are collected for designer fuels with varying ethanol and aromatic species concentrations (and vapor pressures). These results aim to demonstrate how ethanol-influenced VLE can affect the composition evolution of an evaporating fuel, with a 
particular focus on understanding how azeotrope interactions can lead to aromatic enrichment, which may be partially responsible for previously reported observations of increased PM with increased ethanol content. Using a recent distillation curve and droplet evaporation model, a numerical study is performed to explore the coupling of increased HOV and the altered VLE of the fuel with increased ethanol fuel concentrations. Results are presented and the relative influences of these phenomena as it pertains to the PM formation potential of the fuel are discussed.

\section{Experimental Method}

\section{Liquid Fuel Samples}

The Fuel for Advanced Combustion Engines (FACE B) gasoline was used in all distillation curve measurements and analysis. FACE $B$ is a well-characterized gasoline with similar properties to a midgrade gasoline from a pump, as shown by its research octane number (RON) of 96 , but with a much simpler composition and more volatile heavy fractions, with a temperature at $90 \%$ volume distilled (T90) of approximately $120^{\circ} \mathrm{C}$ and a final boiling point (T99) of only $139^{\circ} \mathrm{C}$ [46]. The complete composition of the FACE B can be described by the identification of approximately 30 primary species. The complete composition of the FACE B fuel used in this study was measured using a Detailed Hydrocarbon Analysis (DHA) [47] and is provided in Appendix A. FACE B was blended with 15\% and 30\% ethanol by volume, these blends are referred to E15 and E30. To study the impact of azeotropes on aromatic species evolution, the E0, E15, and E30 fuels were doped with 10\% (by volume) aromatic hydrocarbon species. The blended aromatic species used were cumene, p-cymene and 4-tert-butyltoluene and were chosen to cover a wide range of volatilities, as seen in Table 1. In addition, the E0, E15, and E30 fuels were doped with oxygenated species, including anisole and 4-methylanisole, which were chosen to match the vapor pressures of the aromatic species (cumene and p-cymene). In addition to being potential bio-fuel candidates, the heavy oxygenated species were chosen to explore the impact of chemical structure on added interactivity with the ethanol (as opposed to volatility) and its effect on the VLE of the mixture. The boiling points, $P_{v}(443 \mathrm{~K})$, molecular weight, and DBE of all blended compounds are provided in Table 1. Carbon disulfide was used as the solvent for all the chemical analyses.

\section{Advanced Distillation Curve Measurement}

The Advanced Distillation Curve (ADC) apparatus and method was used for all distillation curve measurements [ $\underline{48}$, $\underline{49}, \underline{50}$. In brief, a temperature controlled heating mantle is placed around a boiling kettle consisting of a $500 \mathrm{ml}$ round bottom flask. The heating mantle assembly sits on a magnetic stirrer that drives a magnetic rod within the kettle to ensure a uniform composition and temperature within the boiling mixture. The temperature of the liquid in the kettle and vapor in the distillation head (just before the entrance to the condenser tube) is monitored with $2 \mathrm{~K}$-type thermocouples. These thermocouples continuously record the temperature using a data acquisition (DAQ) system. The condenser tube is chilled with a $10 \%$ ethylene glycol water solution maintained at $5{ }^{\circ} \mathrm{C}$. This apparatus is equipped with a custom sampling adapter between the condenser tube and a volumetric receiver to withdraw samples of the distillate during the distillation process. The condensed liquid collects in a calibrated volumetric receiver which measures the distilled liquid volume. The receiver is cooled by chilled air from a vortex tube at $2{ }^{\circ} \mathrm{C}$ to help prevent vapor loss. For safety purposes, nitrogen gas is used inside the apparatus to create an oxygen-deprived environment and prevent potential for ignition.

Each distillation experiment is conducted by first loading $200 \mathrm{ml}$ of the desired fuel blend into the distillation kettle. Heating is commenced and the kettle and the distillation head temperature is recorded at a sampling rate of $1 \mathrm{~Hz}$. The heating mantle temperature is continuously adjusted such that it leads the measured boiling fluid temperature by $25^{\circ} \mathrm{C}$. This ensures an even heating throughout the distillation process and a constant distillation rate. Once boiling is achieved, the head temperature will rapidly increase marking the fluid's initial boiling point. The initial boiling temperature (IBT) is determined using previously reported data processing techniques, as described below [51]. The first drop occurs shortly after the sharp change in the head temperature when condensate is noticed to drop into the volumetric receiver. At every $10 \mathrm{~mL}$ distilled (or 5\% volume distilled) the boiling liquid temperature in the kettle (along with the time) is recorded and used to create an accurate distillation curve. Distillation curves for each mixture are measured twice to ensure repeatability. Though multiple attempts were carried out to prevent evaporative volume loss, there were still small losses observed during

TABLE 1 List of additive compounds and associated properties

\begin{tabular}{|c|c|c|c|c|c|c|c|}
\hline Name & Type & CAS \# & MW & $P_{V}(443 K)(\mathrm{kPa})$ & $\operatorname{NBP}\left({ }^{\circ} \mathrm{C}\right)$ & DBE & Density $(298 \mathrm{~K})\left(\mathrm{kg} / \mathrm{m}^{3}\right)$ \\
\hline ethanol & oxygenate & $64-17-5$ & 46 & 1545 & 78 & 0 & 808 \\
\hline cumene & aromatic & $98-82-8$ & 120.2 & 152 & 153 & 4 & 880 \\
\hline p-cymene & aromatic & $99-87-6$ & 134.2 & 84.5 & 177 & 4 & 872 \\
\hline $\begin{array}{l}\text { 4-tertbutyl } \\
\text { toluene }\end{array}$ & aromatic & $98-51-1$ & 148.2 & 58 & 191 & 4 & 861 \\
\hline anisole & oxygenate & $100-66-3$ & 108.1 & 153 & 154 & 4 & 1013 \\
\hline $\begin{array}{l}\text { 4-methyl } \\
\text { anisole }\end{array}$ & oxygenate & $104-93-8$ & 122.2 & 87.7 & 174 & 4 & 969 \\
\hline
\end{tabular}


the distillation. Material loss, as determined by comparing the recovered volume to the initial volume, never exceed $2 \%$ of the initial volume. Nevertheless, this loss was assumed to occur at the onset of boiling of the lightest components, thus all data have been shifted to account for any evaporated material. Furthermore, all distillation measurements were carried out at elevation in Golden, $\mathrm{CO}$ at an average atmospheric pressure of $82.2 \mathrm{kPa}$. All data reported herein represents the raw measurement and has not be shifted to account for the reduced pressure environment at which the measurements were taken.

The IBT of the gasoline-ethanol mixture is difficult to observe and measure without a second thermocouple located in the distillation head [51]. The initial spike in head temperature, after the mixtures start to boil, provides a reference point. A subset of data which includes one hundred seconds before and after the reference point (i.e. 200 data points) are used to fit a tenth order polynomial. The second derivative of the polynomial is plotted versus time and the maximum location (corresponding to the maximum curvature) is used to identify the time of initial boiling of the fuel. The liquid kettle temperature corresponding to this time is then referenced to mark the initial boiling temperature. The boiling temperatures corresponding to every $5 \%$ volume distilled are combined with the IBT to construct the distillation curve.

Throughout the distillation process, samples of the distillate are taken using a specially design sampling hammock located between the condenser and the volumetric receiver [52]. Distillate is collected at first drop, 10\%, 30\%-70\% (in increments of $10 \%$ ), and $90 \%$ volume. The neat fuel sample and the residue in the kettle after the distillation are also sampled for analysis. Approximately $70 \mu \mathrm{L}$ of each sample is withdrawn with a $100 \mu \mathrm{L}$ syringe and inserted into a $2 \mathrm{~mL}$ vial containing $1 \mathrm{~mL}$ of carbon disulfide solution. For the analysis of the samples, the standard test method D6729 was used with the GC-FID [47]. The GC-FID data from each of the samples are imported into Hydrocarbon Expert 5 [푸] , a program used to identify the composition of the samples. The program identifies the present species using a pre-programed retention time index and quantifies their composition by integrating the signal (peak area) recorded by the GC-FID. Calibration was performed with ethanol, anisole, and 4-methyl anisole to determine their relative response factors which is used by the software to correlate a peak area percent to a mass fraction. For all hydrocarbon species present in the FACE B, the pre-programmed RRFs were used as they proved to be highly accurate in measuring the composition of a hydrocarbon mixture.

The transient molar specific $\mathrm{HOV}, \bar{H}_{f g}$, of the mixture as it evaporates is measured using a linear summation of each individual component's HOV multiplied by their mole fraction $\left(y_{i}\right)$ (Eq. 2). Similar techniques were applied to determine the distillation dependent molecular weight which was used to determine mass specific HOVs. The distillation and droplet models were set up to accept the resulting DHA of the neat fuel samples as an input for the initial condition of the simulation.

$$
\bar{H}_{f g, m i x}=\sum_{i} y_{i} \bar{H}_{f g, i}
$$

\section{Simulation Description}

\section{Distillation Model-UNIFAC}

Details of the distillation model can be found in previous work [느] , thus only a brief description is provided here. The prediction of the distillation curves of a complex fuel is carried out by solving the set of differential equations which describe the change of the liquid mole fraction for each individual species with respect to a given change in the total liquid mole fraction. These differential equations, derived from vapor-liquid equilibrium (VLE) expressions combining Raoult's Law and Dalton's Law, are solved iteratively for a given increment of evaporation (defined by the change in mixture liquid mole fraction) until the convergence criteria or equilibrium is met, such that the sum of all species vapor pressures equals the total pressure of the system. The model can account for nonideal vaporization experienced in liquid mixtures containing van der Waals interactions stemming from the presence of polar species (typical of many oxygenated biofuel compounds) by incorporating an interaction term $\left(\gamma_{i}\right)$ in to the determination of the VLE constant (Eq. 3). If liquid molecular interactions are negligible, the interaction term $\gamma$ can be ideally assumed to be unity.

$$
K_{i}=\frac{y_{i}}{x_{i}}=\frac{\gamma_{i} p_{i}^{0}}{p_{\text {tot }}}
$$

A Newton-Raphson Method is used to find the liquid temperature which dictates each species' vapor pressure to satisfy the convergence equilibrium condition [54]. Vapor pressure for each individual species is calculated using coefficient lookup tables based on DIPPR equations, as previously described $[\underline{45}, \underline{55}]$.

For cases when ethanol is present in the mixture, the UNIFAC group contribution theory is used to quantify the gamma term present in the VLE expression (Eq. 3) [ㅁ4, $\underline{56}]$. The term which describes the effect that the polarity of one structure has on the VLE of another are empirically derived and tabulated for varying molecular structures/bond types. The gamma activity coefficient required for each species is also temperature dependent and thus must be iteratively determined as a solution converges to equilibrium. As such, the inclusion of UNIFAC theory greatly increases the compute time for a distillation curve.

A similar composite sum weighted approach, as described above in Eq. 2, is carried out to quantify mixture $\mathrm{HOV}$, molecular weight, and density from the composition predicted by the distillation curve model. The temperature dependent physical properties of each individual species are calculated with the empirical relationships provided in DIPPR [ [55].

Temperature dependent vapor pressure are critical property data needed for the distillation curve and droplet models. There was a lack of vapor pressure data for the 4-methyl anisole available in the DIPPR database, as such, this data was measured using a variable pressure ADC apparatus/procedure [50]. The ADC environment containing $\sim 100 \mathrm{ml}$ of liquid 4-methyl anisole was sealed and vacuumed to $10 \mathrm{kPa}$. Pressures were then increased in a step fashion and the fluid was allow to 
boil at each pressure. The boiling temperature versus pressure for the 4-methyl anisole was then used to fit a modified Antoine curve which was used in the simulations. The measured vapor pressure versus temperature and modified Antoine fit to the data for 4-methyl anisole are included in Appendix B.

\section{Droplet Evaporation Model}

Details of the droplet evaporation model can be found in previous work [45], thus only a brief description is provided here. In brief, the droplet evaporation model applies an energy balance to the previously described distillation curve simulation and uses mass diffusion rates to define the transients of the system. The sensible heat of the droplet is balanced by heat conduction and the latent heat of vaporization. As this is zerodimensional, composition and temperature within the droplet is assumed to be uniform, a reasonable assumption for conditions which exist during the fuel injection of a DISI engine [57]. Mass diffusivity is determined using a mixture average approach utilizing the molecular weight of the fuel vapor-air mixture surrounding the droplet.

It should be noted that this general droplet model is not representative of an actual engine environment as it does not include convective transport phenomena and associated turbulence as well as temperature and concentration gradients experienced within the cylinder. Nevertheless, this model does allow one to compare fuel mixtures and explore the role of physical properties, VLE and HOV, on the influence of droplet lifetimes and droplet compositions. These comparisons can then be used to possibly explain any differences in observed tailpipe PM emissions between a set of fuels.

\section{Results}

\section{Distillation Curve Analysis}

The set of distillation curves for all mixture containing the heavy aromatic compounds (i.e. cumene, p-cymene, and 4-tertbuty toluene) are provided in Figure 2, sorted by ethanol content of the base fuel (i.e. E0, E15, and E30). To allow for inter-plot comparisons, the FACE B - E0 curve is provided in each plot. Sorting the data in this manner allows for comparison between the mixtures containing the different additives. Obviously, the T90 values in each of the distillation curves increase corresponding to the decreasing vapor pressure of the additive used (cumene $\rightarrow$ p-cymene $\rightarrow$ 4-tertbutyl toluene). Going from cumene to p-cymene and to 4-tertbutyl toluene, the final boiling temperatures increase each time by approximately $20^{\circ} \mathrm{C}$.

The distillation curves for all the $\mathrm{p}$-cymene containing mixtures are plotted together in Figure 3. This allows for an easier comparison between mixtures with varying ethanol content. From Figure 3, it is clear to see the influence of ethanol on the depression of the boiling temperatures early in the distillation curve (as compared to the E0 mixtures).
FIGURE 2 Experimentally measured distillation curves for all heavy aromatic containing mixtures sorted by ethanol content, EO (top), E15 (middle), and E30 (bottom). FACE B - EO blend is provided in each figure for reference. All measurements were taken at an average pressure of $81.2 \mathrm{kPa}$.

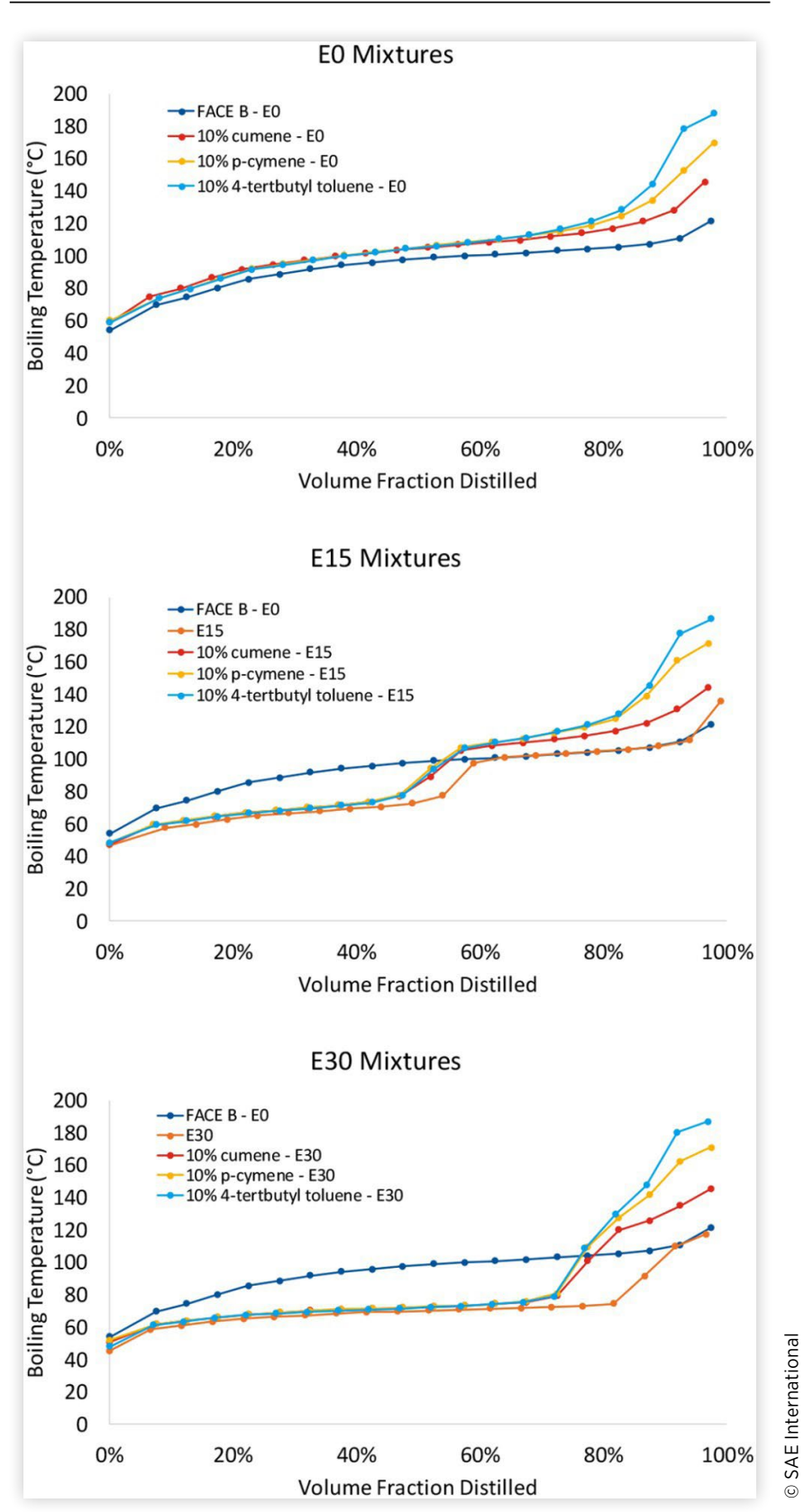

Ethanol in the E15 mixtures suppresses the boiling temperatures until 50\% volume distilled and until nearly $80 \%$ volume distilled for the E30 mixture. The decreased boiling temperatures occur when ethanol is present in the boiling fluid mixture and are a result of the positive azeotropes created between the ethanol and the hydrocarbon compounds. As soon as the ethanol is completely evaporated, boiling temperatures rapidly increase to catch up to the corresponding boiling temperatures in the E0 distillation curve.

Using the sampling feature of the Advanced Distillation Curve approach, the composition of the distillate was 
FIGURE 3 Experimentally measured distillation curves for the mixtures containing p-cymene. FACE B - EO blend is provided in each figure for reference. All measurements were taken at an average pressure of $81.2 \mathrm{kPa}$.

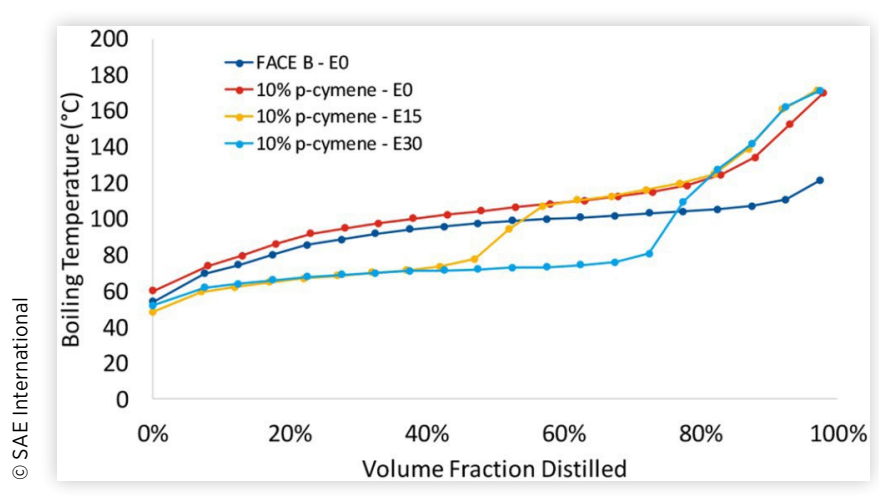

FIGURE 4 Mass fractions of ethanol, iso-octane, and cumene measured in the distillate as a function of volume fraction distilled for all cumene containing blends. All measurements were taken at an average pressure of $81.2 \mathrm{kPa}$.

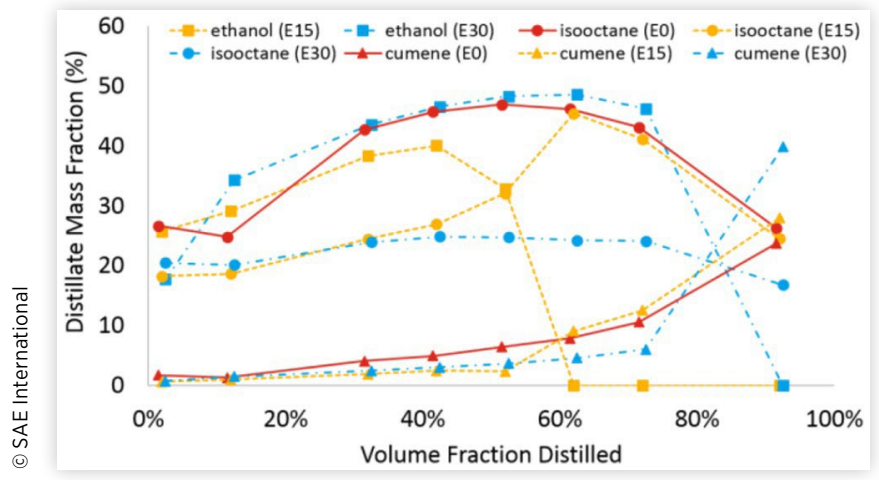

measured to explore the influence of ethanol on the evolving chemical makeup of the boiling fluid. As a representative case, the distillate composition signified by three primary components, ethanol, iso-octane, and the aromatic additive, for all the cumene containing fuel blends as a function of volume distilled are depicted in Figure 4. A few interesting phenomena can be observed in Figure 4. First, the fall of ethanol concentration occurs at the same locations of the rapid rise in boiling temperatures observed in the distillation curves, further indicating the role of ethanol on the suppressed boiling temperature behaviors. Secondly, it can be seen that while ethanol is present in the boiling mixture, it suppresses the vaporization of the other species, including iso-octane and the aromatic additive. This is indicated by the sudden bump in the species concentration immediately after the ethanol has been exhausted. Lastly, it can be seen that increasing the initial ethanol concentration leads to an enrichment of the aromatic species at the tail of the distillation curve. Particularly noticeable, when moving from the E15 mixture to the E30, the cumene mass fraction in the distillate at the $90 \%$ distilled volume fraction increases by more than $40 \%$. It should be noted that all the mixtures with each aromatic additive exhibited similar ethanol influenced aromatic enrichment behavior.
This behavior related to the aromatic enrichment will be discussed in more detail later.

Heavy biofuel oxygenated additives were chosen with nearly identical vapor pressures and normal boiling points as the heavy aromatic species and tested in a similar fashion to explore whether additional interactivity between the ethanol and a heavy oxygenated compound could influence VLE. Distillation curves for the $10 \%$ anisole and the cumene mixtures are provided in Figure 5. The E0 and E15 blends for the two additives provide nearly identical distillation curves. However, as the initial ethanol content is increased to E30, discrepancies are noticed in the turning point marking the moment during the distillation at which ethanol is exhausted from the boiling fluid. The anisole appears to retain the ethanol in the boiling fluid longer than the cumene, most likely as a result of added interactivity.

The distillation dependent composition (ethanol and additive) of the mixtures containing 4-methyl anisole are provided in Figure 6. The ethanol and additive concentration for the p-cymene - E30 mixture is also included for comparison. The enrichment behavior as noted earlier for the aromatic additives is also observed for the heavy oxygenated species.

\section{FIGURE 5 Experimentally measured distillation curves for} the mixtures containing anisole and cumene. All measurements were taken at an average pressure of $81.2 \mathrm{kPa}$.

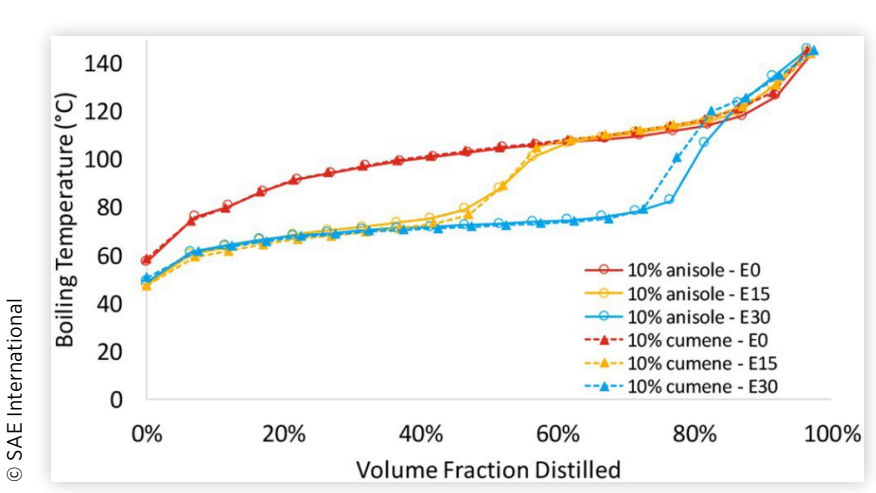

FIGURE 6 Mass fractions of ethanol and 4-methyl anisole measured in the distillate as a function of volume fraction distilled for all 4-methyl anisole containing blends. Compositions from the $\mathrm{p}$-cymene (E30) blends are also included for comparison. All measurements were taken at an average pressure of $81.2 \mathrm{kPa}$.

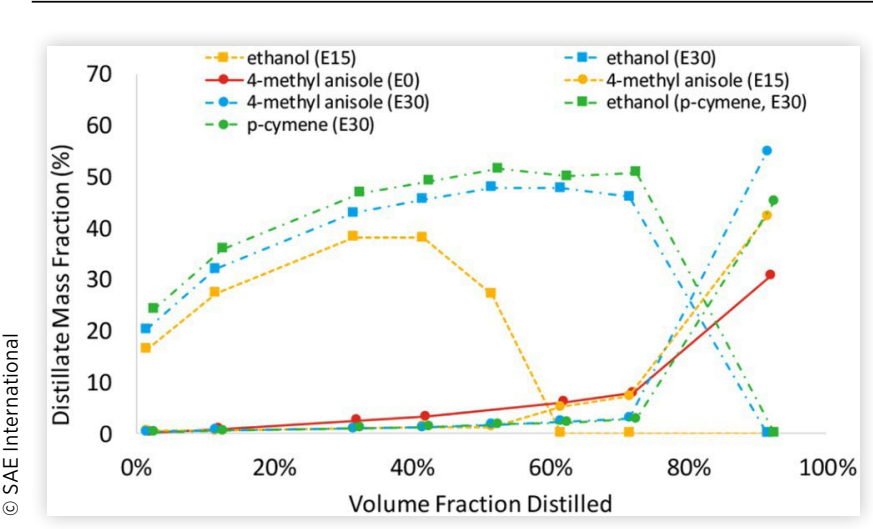


Comparing the additive mass fraction between the $\mathrm{p}$-cymene - E30 and the 4-methyl anisole - E30 blends, a nearly 20\% greater enrichment for the 4-methyl anisole compound is observed compared to that of the p-cymene.

\section{Distillation Curve Modeling Results}

The distillation curve simulations were carried out for all of the same mixtures that were experimentally tested. The predicted distillation curve and distillate compositions are plotted alongside the corresponding experimental measurements for the p-cymene containing fuel mixtures in Figure 7. Overall, there is good agreement between the predicted and measured boiling temperatures and distillate composition. Although difficult to see in Figure 7 (bottom) because of the relative steep gradients in the $\mathrm{p}$-cymene mass fraction curve, the distillation predictions also identify the same additive enrichment behavior as observed experimentally.

There are a couple primary reasons why an increase in initial ethanol content may result in the heavy additive enrichment. The first, stems from the fact that ethanol being a lighter

FIGURE 7 Comparison between the experimentally and simulated distillation curves (top) and the experimentally measured and predicted distillate composition (bottom) for the $\mathrm{p}$-cymene containing fuel blends. All measurements and simulations were carried out at an average pressure of $81.2 \mathrm{kPa}$.

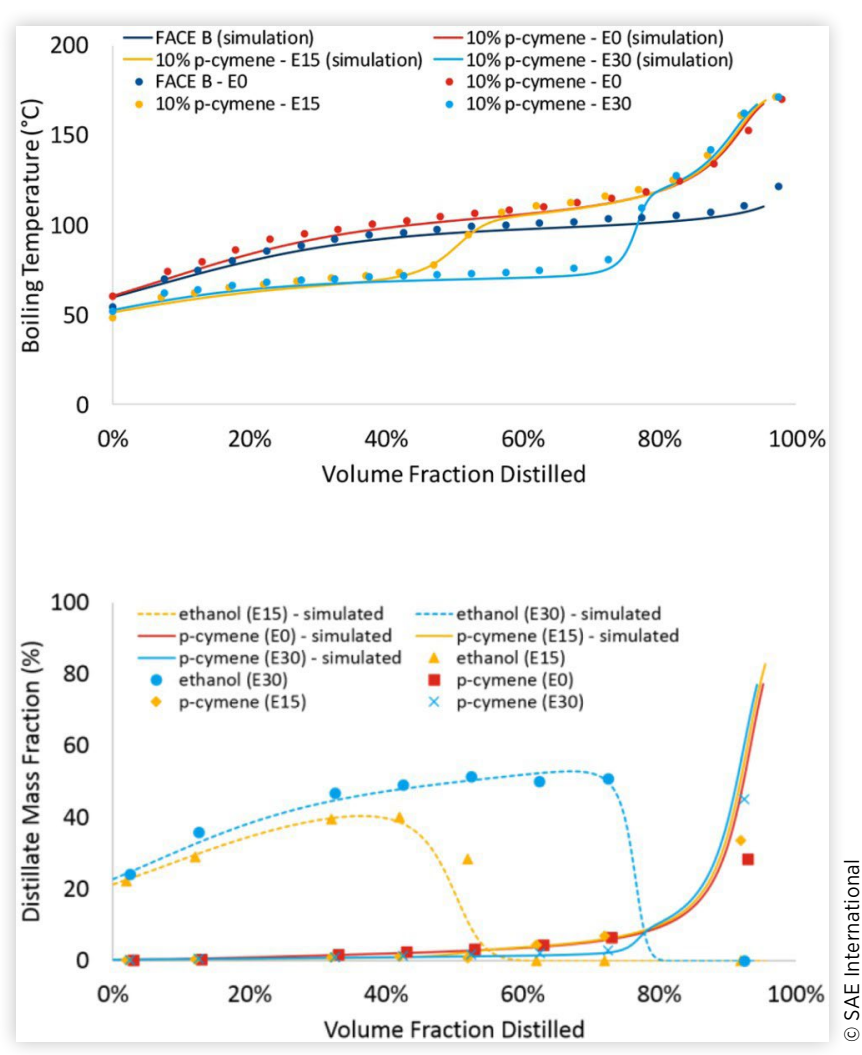

species will influence the early part of the distillation and push the vaporization of the heavy additives towards later in the distillation curve as a result of volatility difference. The second reasoning is that ethanol may interact with the non-aromatic species aiding in their preferential vaporization thus causing the additives to be retained in the liquid phase longer than would be expected. The utility of a numerical simulation is that one can turn on and off parameters to carry out a sensitivity analysis and gain insight regarding the physics of a particular behavior. Another utility is that a simulation can also provide data that is difficult to measure, as for example the transient boiling liquid composition. In an attempt to better understand causes leading to the enrichment of the additive species previously noted, a numerical study was carried out by computing the distillation dependent additive mass fraction in the liquid sample for (1) the realistic case where the interaction parameter is determined using the UNIFAC approach and (2) the case where the gamma term is set ideally to unity (i.e. neglecting liquid intermolecular interactivity). Comparing the ideal to the non-ideal VLE cases will help determine whether the volatility effect is responsible and/or an azeotrope driven preferential vaporization effect is dominant on the observed enrichment.

The liquid additive mass fraction at the $90 \%$ volume fraction distilled for each fuel blend determined using ideal and non-ideal (UNIFAC) approaches are provided in Figure 8. Both the ideal and the UNIFAC simulations result in additive enrichment as ethanol is increased. This signifies that that the volatility driven dilution effect plays a significant role. However, the liquid mass fraction of the additive is always greater in the E30 blends for the simulations accounting for liquid molecular interactions (UNIFAC) as compared to the ideal case. This suggests that, though maybe not the dominant effect, a preferential vaporization phenomenon does partially explain the enrichment of the heavy additives as initial ethanol concentration is increased in the fuel. Furthermore, the differences appear to be greater as the vapor pressure of the additive is increased, likely a result of an increased overlap between the ethanol and the additive species (or compounds with similar volatility) and thus more molecular interaction at/near VLE. Finally, the oxygenated additives display very different trends as compared to the corresponding aromatic additive with

FIGURE 8 Predicted additive mass fraction in the boiling liquid at $90 \%$ volume distilled.

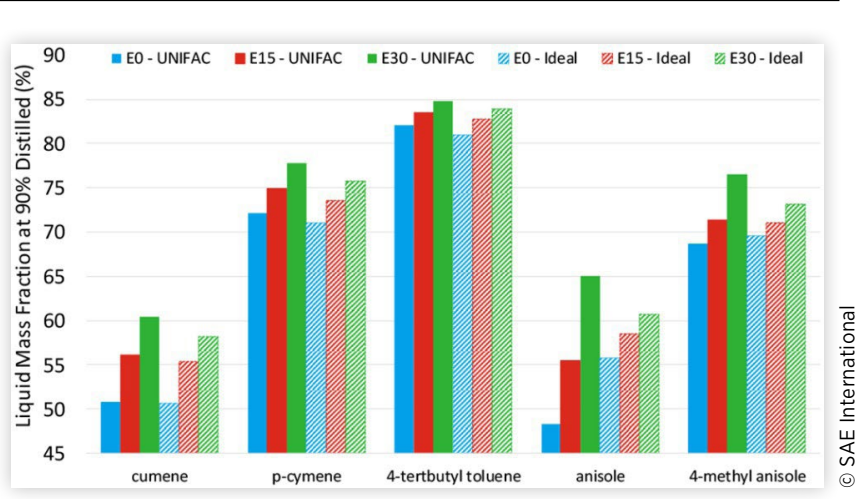


FIGURE 9 Measured and predicted distillation dependent HOV for the $\mathrm{p}$-cymene containing fuel blends.

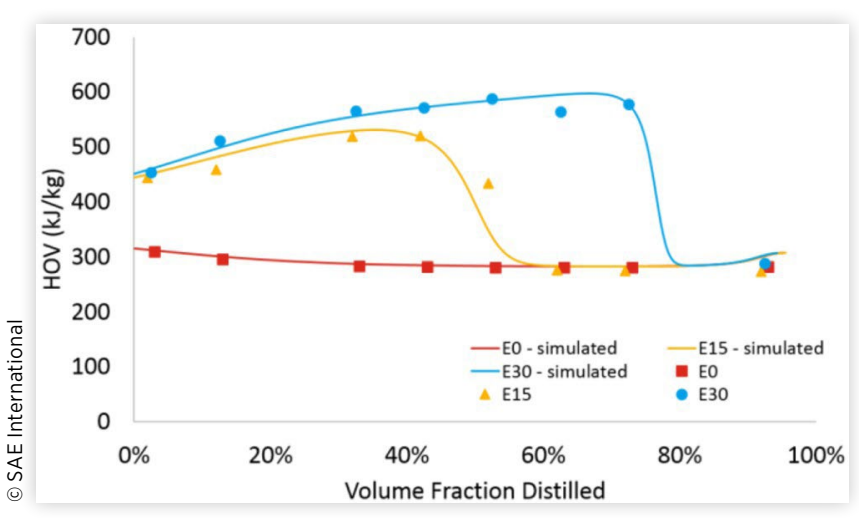

similar vapor pressure. Most notably is the anisole, which has a lower $90 \%$ volume distilled liquid mass fraction without ethanol for the UNIFAC case as compared to the ideal simulation result. This may be due to the anisole having interactions with the lighter hydrocarbon species in the FACE B causing it to be preferentially evaporated. However, as ethanol in increased the opposite trend is observed for the anisole mass fraction, signifying that ethanol maybe preventing the anisole molecule from interacting with the lighter hydrocarbon species and preferentially evaporating ultimately leading to the anisole enrichment.

The measured and predicted distillate composition were used to determine the distillation dependent HOV of the fuel blends (Eq. 2). Comparisons between the modeled and measured HOV for the p-cymene fuel mixtures are provided in Figure 9. Clearly, the HOV is significantly greater (nearly by a factor of two) while ethanol in present in boiling fluid. In addition, the predicted HOV matches trends and magnitudes well with the measured values. The following section discusses the influence of ethanol on droplet lifetime and compositions for the matrix of fuel blends. As such, the HOV is an important term in the energy balance required to describe the droplet temperature and subsequent vapor pressure.

\section{Droplet Model Results}

Modeling the evaporation process of a droplet while accounting for an energy exchange is more representative of the processes that occur in a DISI engine. Furthermore, investigating the dynamics of a droplet also allows one to explore the influence of ethanol's high HOV on droplet lifetimes along with enrichment phenomenon which may help explain recent observations possibly linking ethanol to increased in-cylinder PM formation. The time dependent droplet temperature and droplet diameter (normalized by the initial droplet diameter, $\mathrm{D}_{\mathrm{o}}=25 \mu \mathrm{m}$ ) is plotted in Figure 10 for the FACE B mixtures (i.e. no additive) and the cumene containing fuel blends. The simulations were run in a constant temperature/pressure environment of $315 \mathrm{~K}$ and $1 \mathrm{~atm}$. The initial droplet temperature was set to $25^{\circ} \mathrm{C}$. A $25 \mu \mathrm{m}$ initial droplet diameter was selected as this represents a nominal value in a typical DISI fuel delivery system [ㄷ8]. Droplet lifetimes, marked by the point
FIGURE 10 Predicted constant temperature (315 K) and pressure (1 atm) transient normalized droplet diameter (dotted lines) and droplet temperature (solid lines) for the non-additive mixtures and the cumene containing mixtures. Initial droplet temperature is $298 \mathrm{~K}$ and droplet diameter is $25 \mu \mathrm{m}$.

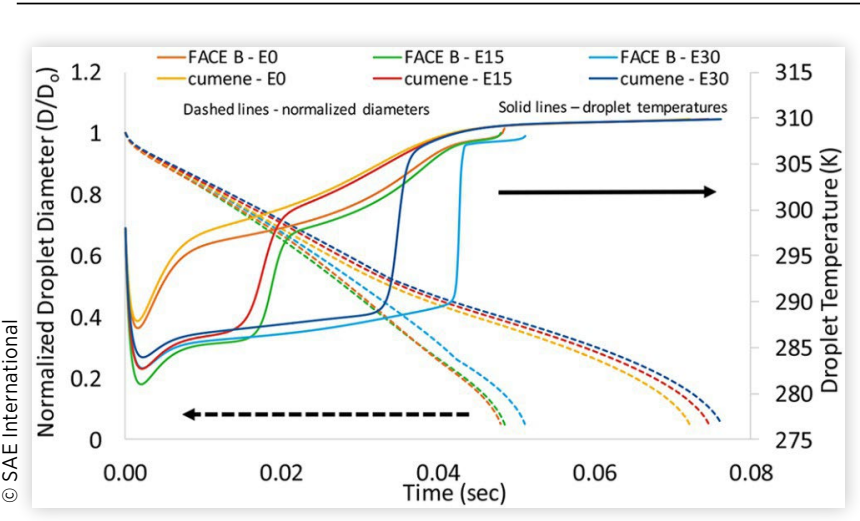

TABLE 2 Predicted droplet lifetimes, $D_{0}=25 \mu \mathrm{m}, \mathrm{T}_{\text {int. drop }}=$ $298 \mathrm{~K}, \mathrm{~T}_{\mathrm{amb}}=315 \mathrm{~K}, \mathrm{P}=1 \mathrm{~atm}$.

\begin{tabular}{|c|c|c|c|}
\hline \multicolumn{4}{|c|}{ Droplet lifetime (ms) } \\
\hline & EO & E15 & E30 \\
\hline FACE B & 48.5 & 48.0 & 51.1 \\
\hline cumene & 72.2 & 74.6 & 76.2 \\
\hline p-cymene & 150.2 & 152.2 & 154.2 \\
\hline $\begin{array}{l}\text { 4-tertbutyl } \\
\text { toluene }\end{array}$ & 344.8 & 364.7 & 369.0 \\
\hline anisole & 85.0 & 88.0 & 93.4 \\
\hline $\begin{array}{l}\text { 4-methyl } \\
\text { anisole }\end{array}$ & 178.8 & 181.0 & 185.4 \\
\hline
\end{tabular}

at which $99.99 \%$ of the initial liquid mole fraction has been evaporated, are increased (nearly by a factor of 2 ) with the addition of $10 \%$ cumene as a result of the decrease in the overall volatility of the fuel. Interestingly, for a given fuel additive, as ethanol concentration is increased the droplet lifetimes also increase. Given that the droplet vapor pressure is a strong function of the droplet temperature, these increase in droplet lifetimes with the addition of ethanol may be explained by the transient droplet temperature, which is reduced by $10-15{ }^{\circ} \mathrm{C}$ when ethanol is present in the liquid droplet and remains depressed longer as the initial ethanol concentration is increased. Droplet lifetimes are tabulated for all of the test fuels in Table 2 and show similar trends as in Figure 10 for the different additives.

The transient liquid additive mass fraction as well as total mass remaining in the droplet are plotted in Figure 11 for the cumene containing fuel blends. The total additive mass thus takes into account both any enrichment effect previously discussed, as well as, slowed droplet evaporation due to increased mixture HOV. Similar to the distillation curves, there is a slight enrichment of the cumene mass fraction in the droplet (between 40-60 ms) as ethanol is increased, however, more pronounced is the effect of the initial ethanol concentration on the total mass of the cumene in the same time span. At the time corresponding to the droplet lifetime of FACE B 
FIGURE 11 Predicted transient cumene mass fraction (dotted lines) and total cumene mass in the liquid droplet for all cumene containing fuel blends.

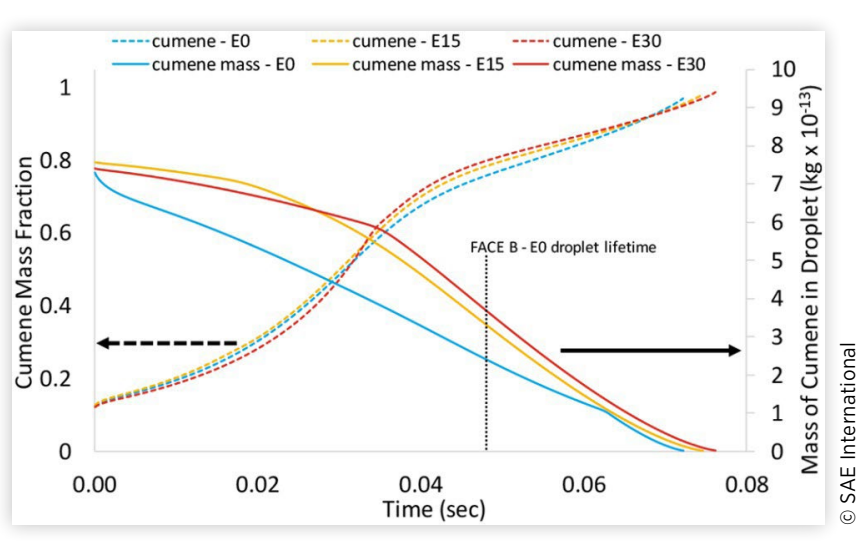

FIGURE 12 Predicted additive mass in liquid droplet at a reference time of $48.5 \mathrm{~ms}$ corresponding to the droplet lifetime of the FACE B - EO mixture.

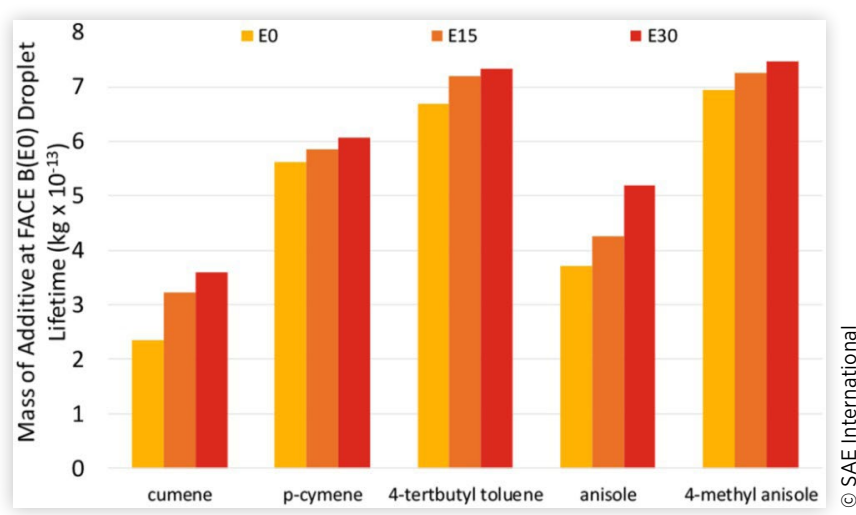

- E0 (48.5 ms), the total mass of cumene in the liquid droplet is increased by approximately $50 \%$ from the E0 blend to the E30 blend. The total additive masses at the reference time marked by the droplet lifetime of the FACE B - E0, for each of the other additive compounds are plotted in Figure 12. Interestingly, the total mass of all the additives increase with increasing initial ethanol concentration with the most significant increases coming for the additives with the highest vapor pressure (cumene and anisole).

\section{Summary/Conclusions}

Distillation curve measurements and droplet simulations were carried out for a carefully designed test fuel matrix to help explore recent observations noticing increased PM emissions for moderate to high ethanol containing fuels. Distillation curve measurements identified an enrichment behavior in which the heavy aromatic or oxygenated species concentrations increased at the tail of the distillation curve as the initial ethanol fuel concentration was increased. A numerical study carried out with a recently developed distillation curve model suggests that azeotrope interactions with the ethanol plays a small role in contributing to this enrichment behavior, especially when the volatility of the aromatic species is closer to that of ethanol. The increased volatility of the mixture when ethanol is present appears to play a more significant role in the enrichment of the heavy species. Droplet simulations carried out for the same fuel mixtures indicate that both the slowed evaporation as a result of the increased HOV when ethanol is present along with the enrichment behaviors noted in the distillation curve can result in significantly more aromatic mass remaining in the liquid phase when the initial ethanol concentration is increased.

These results suggest that for fuels when ethanol is present there is an increased potential for slower evaporation that could contribute to reduced fuel/air mixing and the result of locally fuel rich regions within the cylinder or fuel wall impingement that could lead to increased PM formation upon combustion. Furthermore, depending on the fuel composition, altered VLE when ethanol is present can potentially lead to the enrichment of species that possess a higher chemical kinetic potential to form soot/PM. Future work will include engine testing and PM measurements of the reported test fuel matrix to determine if correlations between the observed phenomenon reported here and PM formation exist. This data will help determine whether future strategies which will predict the PM potential of a fuel containing oxygenated biofuel species should include terms related to the HOV/VLE of a mixture to better represent the relationship of vaporization/mixing potential of the fuel on its PM emissions.

\section{References}

1. Butler, A.D., Sobotowski, R.A., Hoffman, G.J., and Machiele, P., "Influence of Fuel PM Index and Ethanol Content on Particulate Emissions from Light-Duty Gasoline Vehicles," SAE Technical Paper 2015-01-1072, 2015, doi:10.4271/2015-01-1072.

2. Wang, Z., Liu, H., and Reitz, R.D., "Knocking Combustion in Spark-Ignition Engines," Progress in Energy and Combustion Science 61(Supplement C):78-112, 2017, doi:10.1016/j.pecs.2017.03.004.

3. Sakai, S. and Rothamer, D., "Effect of Ethanol Blending on Particulate Formation from Premixed Combustion in SparkIgnition Engines," Fuel 196(Supplement C):154-168, 2017, doi:10.1016/j.fuel.2017.01.070.

4. Laden, F., Schwartz, J., Speizer, F.E., and Dockery, D.W., "Reduction in Fine Particulate Air Pollution and Mortality," American Journal of Respiratory and Critical Care Medicine 173(6):667-672, 2006, doi:10.1164/rccm.200503-443OC.

5. Pope, I.C., Burnett, R.T., Thun, M.J., Calle, E.E. et al., "Lung Cancer, Cardiopulmonary Mortality, and Long-Term Exposure to Fine Particulate Air Pollution," JAMA 287(9):1132-1141, 2002, doi:10.1001/jama.287.9.1132.

6. Pope, C.A., Burnett, R.T., Thurston, G.D., Thun, M.J. et al., "Cardiovascular Mortality and Long-Term Exposure to Particulate Air Pollution," Epidemiological Evidence of General Pathophysiological Pathways of Disease 109(1):71-77, 2004, doi:10.1161/01.cir.0000108927.80044.7f. 
7. Dockery, D.W., Pope, C.A., Xu, X., Spengler, J.D. et al., “An Association between Air Pollution and Mortality in Six U.S. Cities," New England Journal of Medicine 329(24):1753-1759, 1993, doi:10.1056/nejm199312093292401.

8. Ahmed, A., Waqas, M., Naser, N., Singh, E. et al., "Compositional Effects of Gasoline Fuels on Combustion, Performance and Emissions in Engine," SAE Int. J. Fuels Lubr. 9(3):460-468, 2016, doi:10.4271/2016-01-2166.

9. Khalek, I.A., Bougher, T., and Jetter, J.J., "Particle Emissions from a 2009 Gasoline Direct Injection Engine Using Different Commercially Available Fuels," SAE Int. J. Fuels Lubr. 3(2):623-637, 2010, doi:10.4271/2010-01-2117.

10. Richter, H., Benish, T.G., Mazyar, O.A., Green, W.H. et al., "Formation of Polycyclic Aromatic Hydrocarbons and Their Radicals in a Nearly Sooting Premixed Benzene Flame," Proceedings of the Combustion Institute 28(2):2609-2618, 2000, doi:10.1016/S0082-0784(00)80679-7.

11. McEnally, C.S. and Pfefferle, L.D., "Improved Sooting Tendency Measurements for Aromatic Hydrocarbons and their Implications for Naphthalene Formation Pathways," Combustion and Flame 148(4):210-222, 2007, doi:10.1016/j. combustflame.2006.11.003.

12. Watson, R.J., Botero, M.L., Ness, C.J., Morgan, N.M. et al., "An Improved Methodology for Determining Threshold Sooting Indices from Smoke Point Lamps," Fuel 111(Supplement C):120-130, 2013, doi:10.1016/j. fuel.2013.04.024.

13. Li, W., Collins, J.F., Durbin, T.D., Huai, T. et al., "Detection of Gasoline Vehicles with Gross PM Emissions," SAE Technical Paper 0148-7191, 2007, doi:10.4271/0148-7191.

14. Aikawa, K., Sakurai, T., and Jetter, J.J., "Development of a Predictive Model for Gasoline Vehicle Particulate Matter Emissions," SAE Int. J. Fuels Lubr. 3(2):610-622, 2010, doi:10.4271/2010-01-2115.

15. "Monthly Energy Review," 2017.

16. Wang, M., Saricks, S., and Santini, D., "Effects of Fuel Ethanol Use on Fuel-Cycle Energy and Greenhouse Gas Emissions," 1999.

17. Wang, M.Q., Han, J., Haq, Z., Tyner, W.E. et al., "Energy and Greenhouse Gas Emission Effects of Corn and Cellulosic Ethanol with Technology Improvements and Land Use Changes," Biomass and Bioenergy 35(5):1885-1896, 2011, doi:10.1016/j.biombioe.2011.01.028.

18. Chupka, G.M., Christensen, E., Fouts, L., Alleman, T.L. et al., "Heat of Vaporization Measurements for Ethanol Blends Up To 50 Volume Percent in Several Hydrocarbon Blendstocks and Implications for Knock in SI Engines," SAE Int. J. Fuels Lubr. 8(2):251-263, 2015, doi:10.4271/201501-0763.

19. Ratcliff, M.A., Burton, J., Sindler, P., Christensen, E. et al., "Knock Resistance and Fine Particle Emissions for Several Biomass-Derived Oxygenates in a Direct-Injection SparkIgnition Engine," SAE Int. J. Fuels Lubr. 9(1):59-70, 2016, doi:10.4271/2016-01-0705.

20. Cooney, C.P., Worm, J.J., and Naber, J.D., "Combustion Characterization in an Internal Combustion Engine with Ethanol-Gasoline Blended Fuels Varying Compression Ratios and Ignition Timing," Energy \& Fuels 23(5):23192324, 2009, doi:10.1021/ef800899r.
21. Kasseris, E. and Heywood, J.B., "Charge Cooling Effects on Knock Limits in SI DI Engines Using Gasoline/Ethanol Blends: Part 1-Quantifying Charge Cooling," SAE Technical Paper 2012-01-1275, 2012, doi:10.4271/2012-01-1275.

22. ASTM International, "Standard Test Method for Research Octane Number of Spark-Ignition Engine Fuel,” 2016.

23. Leone, T.G., Olin, E.D., Anderson, J.E., Jung, H.H. et al., "Effects of Fuel Octane Rating and Ethanol Content on Knock, Fuel Economy, and $\mathrm{CO}_{2}$ for a Turbocharged DI Engine," SAE Int. J. Fuels Lubr. 7(1):9-28, 2014, doi:10.4271/2014-01-1228.

24. Jung, H.H., Leone, T.G., Shelby, M.H., Anderson, J.E. et al., "Fuel Economy and $\mathrm{CO}_{2}$ Emissions of Ethanol-Gasoline Blends in a Turbocharged DI Engine," SAE Int. J. Engines, 6(1):422-434, 2013, doi:10.4271/2013-01-1321.

25. Sluder, C.S., Szybist, J.P., McCormick, R.L., Ratcliff, M.A. et al., "Exploring the Relationship between Octane Sensitivity and Heat-of-Vaporization," SAE Int. J. Fuels Lubr. 9(1):80-90, 2016, doi:10.4271/2016-01-0836.

26. Chupka, G.M., Christensen, E., Fouts, L., Alleman, T.L. et al., "Heat of Vaporization Measurements for Ethanol Blends up to 50 Volume Percent in Several Hydrocarbon Blendstocks and Implications for Knock in SI Engines," SAE Int. J. Fuels Lubr. 8(2):251-263, 2015, doi:10.4271/2015-01$\underline{0763}$.

27. Kasseris, E. and Heywood, J.B., "Charge Cooling Effects on Knock Limits in SI DI Engines Using Gasoline/Ethanol Blends: Part 2-Effective Octane Numbers," SAE Int. J. Fuels Lubr. 5(2):844-854, 2012, doi:10.4271/2012-01-1284.

28. EPA, "Regulation To Mitigate the Misfueling of Vehicles and Engines With Gasoline Containing Greater Than Ten Volume Percent Ethanol and Modifications to the Reformulated and Conventional Gasoline Programs," E. P. Agency RIN 2060-AQ17, 2011.

29. Splitter, D. and Szybist, J., "Intermediate Alcohol-Gasoline Blends, Fuels for Enabling Increased Engine Efficiency and Powertrain Possibilities," SAE Int. J. Fuels Lubr. 7(1), 2014, doi:10.4271/2014-01-1231.

30. Nakata, K., Utsumi, S., Ota, A., Kawatake, K. et al., "The Effect of Ethanol Fuel on a Spark Ignition Engine," SAE Technical Paper 2006-01-3380, 2006, 10.4271/2006-01$\underline{3380}$.

31. Mittal, M., Schock, H., and Zhu, G., "In-Cylinder Combustion Visualization of a Direct-injection Sparkignition Engine with Different Operating Conditions and Fuels," SAE Technical Paper 2012-01-1644, 2012, doi:10.4271/2012-01-1644.

32. Catapano, F., Di Iorio, S., Luise, L., Sementa, P. et al., "InCylinder Soot Formation and Exhaust Particle Emissions in a Small Displacement Spark Ignition Engine Operating with Ethanol Mixed and Dual Fueled with Gasoline," SAE Technical Paper 2017-01-0653, 2017, doi:10.4271/2017-01$\underline{0653}$.

33. Broustail, G., Seers, P., Halter, F., Moréac, G. et al., "Experimental Determination of Laminar Burning Velocity for Butanol and Ethanol Iso-Octane Blends," Fuel 90(1):1-6, 2011, doi:10.1016/j.fuel.2010.09.021.

34. Maricq, M.M., Szente, J.J., and Jahr, K., “The Impact of Ethanol Fuel Blends on PM Emissions from a Light-Duty 
GDI Vehicle," Aerosol Science and Technology 46(5):576-583, 2012, doi:10.1080/02786826.2011.648780.

35. Fatouraie, M., Wooldridge, M.S., Petersen, B.R., and Wooldridge, S.T., "Effects of Ethanol on in-Cylinder and Exhaust Gas Particulate Emissions of a Gasoline Direct Injection Spark Ignition Engine," Energy \& Fuels 29(5):33993412, 2015, doi:10.1021/ef502758y.

36. Hirose, T., Komoriya, H., Kojima, M., Tanaka, T. et al., "Effects of ETBE and EtOH Blending in Gasoline on PM Emission from a Direct Injection Spark Ignition Vehicle," SAE Technical Paper 2007-01-4084, 2007, doi:10.4271/200701-4084.

37. Storey, J.M., Barone, T., Norman, K., and Lewis, S., "Ethanol Blend Effects On Direct Injection Spark-Ignition Gasoline Vehicle Particulate Matter Emissions," SAE Int. J. Fuels Lubr. 3(2):650-659, 2010, doi:10.4271/2010-01-2129.

38. He, X., Ireland, J. C., Zigler, B. T., Ratcliff, M. A. et al., “The Impacts of Mid-level Biofuel Content in Gasoline on SIDI Engine-out and Tailpipe Particulate Matter Emissions," 2010.

39. Storch, M., Koegl, M., Altenhoff, M., Will, S. et al., "Investigation of Soot Formation of Spark-Ignited EthanolBlended Gasoline Sprays with Single- and Multi-Component Base Fuels," Applied Energy 181:278-287, 2016, doi:10.1016/j. apenergy.2016.08.059.

40. Chen, L., Stone, R., and Richardson, D., "A Study of Mixture Preparation and PM Emissions Using a Direct Injection Engine Fuelled with Stoichiometric Gasoline/Ethanol Blends," Fuel 96:120-130, 2012, doi:10.1016/j.fuel.2011.12.070.

41. Chen, L., Braisher, M., Crossley, A., Stone, R. et al., "The Influence of Ethanol Blends on Particulate Matter Emissions from Gasoline Direct Injection Engines," SAE Technical Paper 2010-01-0793, 2010, doi:10.4271/2010-01-0793.

42. Price, P., Twiney, B., Stone, R., Kar, K. et al., "Particulate and Hydrocarbon Emissions from a Spray Guided Direct Injection Spark Ignition Engine with Oxygenate Fuel Blends," SAE Technical Paper 2007-01-0472, 2007, doi:10.4271/2007-01-0472.

43. Matti Maricq, M., "Soot Formation in Ethanol/Gasoline Fuel Blend Diffusion Flames," Combustion and Flame 159(1):170180, 2012, doi:10.1016/j.combustflame.2011.07.010.

44. Storey, J.M., Lewis, S., Szybist, J., Thomas, J. et al., "Novel Characterization of GDI Engine Exhaust for Gasoline and Mid-Level Gasoline-Alcohol Blends," SAE Int. J. Fuels Lubr. 7(2):571-579, 2014, doi:10.4271/2014-01-1606.

45. Burke, S., Ratcliff, M., McCormick, R., Rhoads, R. et al., "Distillation-Based Droplet Modeling of Non-Ideal Oxygenated Gasoline Blends: Investigating the Role of Droplet Evaporation on PM Emissions," SAE Int. J. Fuels Lubr. 10(1), 2017, doi:10.4271/2017-01-0581.

46. Cannella, W., Foster, M., Gunter, G., and Leppard, W., "FACE Gasolines and Blends with Ethanol: Detailed Characterization of Physical and Chemical Properties,"Coordinating Research Council, Inc., Alpharetta, 2014.

47. ASTM International, "Standard Test Method for Determination of Individual Components in Spark Ignition Engine Fuels by 100 Metre Capillary High Resolution Gas Chromatography," 2014.
48. Bruno, T.J., "Improvements in the Measurement of Distillation Curves. 1. A Composition-Explicit Approach," Industrial and Engineering Chemistry Research 45(12):43714380, 2006, doi:10.1021/ie051393j.

49. Bruno, T.J., Ott, L.S., Smith, B.L., and Lovestead, T.M., "Complex Fluid Analysis with the Advanced Distillation Curve Approach," Analytical Chemistry 82(3):777-783, 2010, doi:10.1021/ac902002j.

50. Windom, B.C. and Bruno, T.J., "Improvements in the Measurement of Distillation Curves. 5. Reduced Pressure Advanced Distillation Curve Method," Industrial and Engineering Chemistry Research 50(2):1115-1126, 2011, doi:10.1021/ie101784g.

51. Ferris, A.M. and Rothamer, D.A., "Methodology for the Experimental Measurement of Vapor-Liquid Equilibrium Distillation Curves Using a Modified ASTM D86 Setup," Fuel 182:467-479, 2016, doi:10.1016/j.fuel.2016.05.099.

52. Bruno, T.J., Ott, L.S., Lovestead, T.M., and Huber, M.L., “The Composition-Explicit Distillation Curve Technique: Relating Chemical Analysis and Physical Properties of Complex Fluids," Journal of Chromatography A 1217(16):2703-2715, 2010, doi:10.1016/j.chroma.2009.11.030.

53. Hydrocarbon Expert (Version 5), Software, Separation Systems, Inc., Gulf Breeze, FL, 2015.

54. Backhaus, J., "Design Methodology of Bio-Derived Gasoline Fuels,"M.S., Mechanical Engineering, University of Wisconsin, Madison, 2013.

55. The DIPPR Information and Data Evaluation Manager for the Design Institute for Physical Properties (Version 9.1.0), Software, BYU Thermophysical Properties Laboratory, Provo, Utah, 2014.

56. Govindaraju, P.B. and Ihme, M., "Group Contribution Method for Multicomponent Evaporation with Application to Transportation Fuels," International Journal of Heat and Mass Transfer 102:833-845, 2016, doi:10.1016/j. ijheatmasstransfer.2016.06.079.

57. Law, C.K., "Multicomponent Droplet Combustion with Rapid Internal Mixing," Combustion and Flame 26:219-233, 1976, doi:10.1016/0010-2180(76)90073-0.

58. Jankowski, A., Sandel, A., Seczyk, J., and SieminskaJankowska, B., "Analysis of Fuel Spray Preparation for Internal Combustion Engines," Journal of KONES Internal Combustion Engines 1(2):323-332, 2002.

\section{Contact Information}

\section{Bret Windom}

Colorado State University

Bret.Windom@colostate.edu

970-491-7794

\section{Acknowledgments}

This work was supported in part by the U.S. Department of Energy, Office of Science, Office of Workforce Development for Teachers and Scientists (WDTS) under the Visiting Faculty Program (VFP). 
Research performed by National Renewable Energy Laboratory staff was conducted as part of the Co-Optimization of Fuels \& Engines (Co-Optima) project sponsored by the U.S. Department of Energy (DOE) Office of Energy Efficiency and Renewable Energy (EERE), Bioenergy Technologies and Vehicle Technologies Offices. Co-Optima is a collaborative project of multiple National Laboratories initiated to simultaneously accelerate the introduction of affordable, scalable, and sustainable biofuels and high-efficiency, low-emission vehicle engines. Work at the National Renewable Energy Laboratory was performed under Contract No. DE347AC36-99GO10337.

\section{Definitions/Abbreviations}

\author{
ADC - Advanced Distillation Curve \\ DBE - Double bond equivalence
}

DHA - Detailed hydrocarbon analysis

DIPPR - Design Institute for Physical Properties

DISI - Direct-injection spark ignition

FACE - Fuels for Advance Combustion Engines

HOV - Heat of vaporization

NBP - Normal Boiling Point

ODE - Ordinary differential equation

PM - Particulate matter

RVP - Reid Vapor Pressure

UNIFAC - UNIQUAC functional-group activity coefficients VLE - Vapor-liquid equilibrium 


\section{Appendix A}

TABLE 1 Normalized composition of FACE B used for simulation

\begin{tabular}{|l|l|l|}
\hline Component & Group & Percent Weight \\
\hline i-Butane & I-Paraffins & 0.045 \\
\hline n-Butane & Paraffin & 2.305 \\
\hline i-Pentane & I-Paraffins & 8.013 \\
\hline n-Pentane & Paraffin & 2.942 \\
\hline 2,3-Dimethylbutane & I-Paraffins & 0.806 \\
\hline 2-Methylpentane & I-Paraffins & 0.234 \\
\hline 3-Methylpentane & I-Paraffins & 0.105 \\
\hline 2,4-Dimethylpentane & I-Paraffins & 4.241 \\
\hline 2-Methylhexane & I-Paraffins & 9.265 \\
\hline 3-Methylhexane & I-Paraffins & 0.156 \\
\hline 2,2,4-Trimethylpentane & I-Paraffins & 40.732 \\
\hline 2,2,3-Trimethylpentane & I-Paraffins & 0.673 \\
\hline 2,5-Dimethylhexane & I-Paraffins & 1.353 \\
\hline 2,4-Dimethylhexane & I-Paraffins & 1.939 \\
\hline 2,3,4-Trimethylpentane & I-Paraffins & 9.078 \\
\hline 2,3,3-Trimethylpentane & I-Paraffins & 6.116 \\
\hline 2,3-Dimethylhexane & I-Paraffins & 1.856 \\
\hline 4-Methylheptane & I-Paraffins & 0.129 \\
\hline 3,4-Dimethylhexane & I-Paraffins & 0.147 \\
\hline 2,2,5-Trimethylhexane & I-Paraffins & 1.266 \\
\hline 2,3,5-Trimethylhexane & I-Paraffins & 0.212 \\
\hline Ethylbenzene & Mono-Aromatics & 1.200 \\
\hline m-Xylene & Mono-Aromatics & 3.693 \\
\hline p-Xylene & Mono-Aromatics & 1.573 \\
\hline 2,3-Dimethylheptane & I-Paraffins & 0.065 \\
\hline o-Xylene & Mono-Aromatics & 1.516 \\
\hline 2,2,4-trimethylheptane & I-Paraffins & 0.193 \\
\hline n-Nonane & Paraffin & 0.092 \\
\hline 2,3-Dimethyloctane(1) & I-Paraffins & 0.054 \\
\hline & & \\
\hline
\end{tabular}

\section{Appendix B}

The temperature dependent vapor pressure for 4-methyl anisole was measured and utilized in the distillation curve and droplet simulations for blends containing this species. The following equation was used to determine the 4-methyl anisole vapor pressure. The constants were determined from a fit of experimentally measured data. The derived constants and the raw experimental data measured vapor pressure versus temperature are provided below.

$$
P_{\text {vap }, i}=\exp \left[A_{i}+\frac{B_{i}}{T}+C_{i} \ln T+D_{i} T^{E_{i}}\right](P a)
$$

TABLE 2 Measured vapor pressure versus temperature for 4-methyl anisole.

\begin{tabular}{|l|l|}
\hline Temperature (K) & Vapor Pressure $\mathbf{( P a )}$ \\
\hline 379.95 & 10615.00 \\
\hline 384.40 & 12682.86 \\
\hline 389.08 & 14819.64 \\
\hline 395.19 & 18472.86 \\
\hline 398.15 & 20402.86 \\
\hline 401.55 & 22815.36 \\
\hline 405.45 & 25848.21 \\
\hline 409.20 & 29294.64 \\
\hline 413.65 & 33912.86 \\
\hline 417.75 & 38668.93 \\
\hline 420.95 & 42253.21 \\
\hline 424.55 & 46940.36 \\
\hline 426.85 & 50180.00 \\
\hline 428.45 & 52385.71 \\
\hline 430.35 & 55556.43 \\
\hline 431.55 & 57210.71 \\
\hline 433.25 & 59830.00 \\
\hline 434.65 & 62173.57 \\
\hline 436.25 & 64861.79 \\
\hline 437.75 & 67205.36 \\
\hline 439.05 & 69686.79 \\
\hline 439.70 & 71410.00 \\
\hline 440.55 & 72995.36 \\
\hline 440.80 & 73822.50 \\
\hline 441.25 & 74580.71 \\
\hline 447.25 & 85264.64 \\
\hline 448.65 & 101325.00 \\
\hline & \\
\hline
\end{tabular}

TABLE 1 Derived coefficients from measured vapor pressure data for 4-methyl anisole to be used in Eq. 1B.

\begin{tabular}{|c|c|c|c|c|c|}
\hline & $\mathbf{A}$ & B & C & D & $\mathbf{E}$ \\
\hline Vapor Pressure Coefficients & 63.04997218 & -7765.037734 & -5.620039783 & $0.00 E+00$ & 6 \\
\hline
\end{tabular}

